http://dx.doi.org/10.21707/gs.v11.n04a09

\title{
EFEITO DA PREDAÇÃO DE SEMENTES POR MICROLEPIDÓPTEROS NA GERMINAÇÃO E NO DESENVOLVIMENTO INICIAL DE HANDROANTHUS SPONGIOSUS (RIZZini) S. Grose (BigNONIACEAE), UMA ESPÉCIE ARBÓREA ENDÊMICA dA CAATINGA E AMEAÇADA DE EXTINÇÃo
}

\author{
Jéssica Viviane Amorim Ferreira ${ }^{1 *}$, Marcos Vinicius Meiado ${ }^{2}$, José Alves de Siqueira Filho ${ }^{1}$
}

\author{
${ }^{1}$ Colegiado Acadêmico de Ciências Biológicas, Campus de Ciências Agrárias, Universidade Federal do Vale do São Francisco. BR 407, Km 12, Lote 543, \\ Projeto de Irrigação Nilo Coelho C1, Petrolina, Pernambuco, Brasil. CEP: 56300-990. \\ ${ }^{2}$ Laboratório de Fisiologia de Sementes, Departamento de Biociências, Universidade Federal de Sergipe. Av. Vereador Olimpio Grande, s/n, Bloco D, \\ Campus Professor Alberto Carvalho, Bairro Porto, Itabaiana, Sergipe, Brasil. CEP: 49510-200. \\ *Autor para correspondência: jessicaviviane.f@gmail.com
}

Recebido em 08 de janeiro de 2017. Aceito em 17 de agosto de 2017. Publicado em 30 de dezembro de 2017.

REsumo - Os cotilédones são estruturas morfológicas que armazenam nutrientes e tem a função de transferi-los para a plântula em desenvolvimento até o seu estabelecimento e o início da fotossíntese. Estudos sobre a predação de sementes na Caatinga ainda são raros, principalmente com espécies ameaçadas de extinção como Handroanthus spongiosus (Rizzini) S. Grose (Bignoniaceae). Assim sendo, o objetivo deste estudo foi avaliar o efeito da predação de sementes de H. spongiosus por microlepidópteros em seu comportamento germinativo e desenvolvimento inicial. Para isso foram coletados frutos de 10 árvores no município de Casa Nova, Estado da Bahia, e as sementes foram separadas em duas categorias (sementes intactas e sementes predadas) e colocadas para germinar em água destilada. Após a germinação, as sementes foram transferidas para sacos plásticos contendo $500 \mathrm{~g}$ de substrato, os quais foram mantidos em estufa por um período de 90 dias. Os resultados mostraram um padrão germinativo similar entre os tratamentos avaliados. Entretanto, sementes predadas pelos microlepidópteros apresentaram uma redução de cerca de $50 \%$ na germinabilidade quando comparada com a germinação das sementes íntegras. Observaram-se, ainda, diferenças significativas entre as plântulas provenientes de sementes íntegras e sementes predadas. Os resultados mostram que a predação de sementes de H. spongiosus por microlepdopteros é uma ameaça ao estabelecimento de novas populações dessa espécie.

Palavras-chave: CaAtinga; Cascudo; GerminaÇão; Sementes Predadas; Plântula.

EFFECT OF SEED PREDATION BY MICROLEPIDOPTERAN ON GERMINATION AND EARLY DEVELOPMENT OF HANDROANTHUS spongiosus (Rizzini) S. Grose (Bignoniaceae), a tree species Endemic to the CaATinga and THREATENEd With EXTINCTION

AвSTRACT - Cotyledons are morphological structures that store nutrients and have the function of transferring them to the developing seedlings until their establishment and the beginning of photosynthesis. Studies on seed predation in the Caatinga are still rare, especially with endangered species such as Handroanthus spongiosus (Rizzini) S. Grose (Bignoniaceae). Therefore, the aim of this study was to evaluate the effect of predation of $H$. spongiosus seeds by microlepidopterans on their germinative behavior and initial development. Fruits of 10 trees were collected in the municipality of Casa Nova, State of Bahia, and seeds were separated into two categories (intact seeds and predated seeds) and placed to germinate in distilled water. After germinating, the seeds were transferred to plastic bags containing $500 \mathrm{~g}$ of substrate, which were kept in a greenhouse for a period of 90 days. The results showed a similar germinative pattern among the evaluated treatments. However, seeds predated by the microlepidopterans presented a reduction of about $50 \%$ in germinability when compared 
to the germination of the intact seeds. Significant differences were also observed between seedlings from intact seeds and predated seeds. The results show that the predation of $H$. spongiosus seeds by microlepidopterans is a threat to the establishment of new populations of this species.

Keywords: CaAtinga; Cascudo; Germination; Predated Seeds; Seedling.

EFECTO DE LA DEPREDACIÓN DE SEMILLAS POR LOS MICROLEPIDÓPTEROS EN LA GERMINACIÓN Y EN EL CRECIMIENTO inicial de Handroanthus spongiosus (Rizzini) S. Grose (Bignoniaceae), una especie arbórea endémica de la CAATINGA Y AMENAZADA DE EXTiNCIÓN

REsumen - Los cotiledones son estructuras morfológicas que almacenan nutrientes y tienen la función de transferirlos a las plántulas en desarrollo hasta su establecimiento y el inicio de la fotosíntesis. Los estudios sobre la depredación de semillas en la Caatinga todavía son raros, especialmente con especies amenazadas como Handroanthus spongiosus (Rizzini) S. Grose (Bignoniaceae). Por lo tanto, se objetivó en este estudio evaluar el efecto de la depredación de las semillas de $H$. spongiosus por microlepidópteros sobre su comportamiento germinativo y crecimiento inicial. Se recolectaron frutos de 10 árboles en el municipio de Casa Nova, estado de Bahía, y se separaron las semillas en dos categorías (semillas intactas y semillas depredadas) y se colocaron para germinar en agua destilada. Después de la germinación, se transfirieron las semillas a bolsas de plástico que contenían $500 \mathrm{~g}$ de sustrato, que se mantuvieron en un invernadero durante un período de 90 días. Se observó un patrón germinativo similar entre los tratamientos evaluados. Sin embargo, las semillas depredadas por los microlepidópteros presentaron una reducción de aproximadamente el 50\% en la germinabilidad en comparación con la germinación de las semillas intactas. También se observaron diferencias significativas entre las plántulas de las semillas intactas y de las semillas depredadas. Los resultados muestran que la depredación de las semillas de H. spongiosus por microlepidópteros es una amenaza para el establecimiento de nuevas poblaciones de esta especie.

Palabras clave: Caatinga; Cascudo; Germinación; Semillas Depredadas; Plántulas.

\section{INTRODUÇÃO}

Os cotilédones são estruturas morfológicas que armazenam nutrientes que auxiliam a germinação e o desenvolvimento inicial da plântula até o estabelecimento e início da fotossíntese (Taiz e Zeiger 2006). As substâncias de reservas são usadas, na fase inicial de germinação e desenvolvimento, como fonte de energia necessária para manter as funções vitais do embrião, que irá se desenvolver e se estabelecer no ambiente (Melo et al. 2004, Baskin e Baskin 2014). Durante esse processo, os cotilédones, gradativamente, diminuem de tamanho, murcham e, finalmente, se desprendem da plântula. Nesse momento, o indivíduo estabelecido já é capaz de realizar a fotossíntese e não depende mais do material armazenado nos tecidos de reserva das sementes para a sua nutrição (Melo et al. 2004).

Diversos fatores afetam o estabelecimento, o desenvolvimento inicial e a sobrevivência das plântulas em campo como, por exemplo, os patógenos, a restrição hídrica, os danos mecânicos, a herbivoria e a competição intra e interespecífica. A maneira como cada espécie vegetal responde a esses fatores é determinada por adaptações das plântulas, as quais representam respostas evolutivas frente a esses fatores (Melo et al. 2004). Além disso, a quantidade e a qualidade das reservas das sementes, bem como a morfologia funcional dos cotilédones, também podem influenciar essa fase inicial de desenvolvimento das plântulas (Melo et al. 2004). Reduções significativas no crescimento e no potencial reprodutivo dos indivíduos em fase adulta são observadas em Lithocarpus densiflora (Hook. \& Arn.) (Fagaceae) que tiveram seus cotilédones removidos artificialmente no início do desenvolvimento 
das plântulas (Kennedy et al. 2004). Porém, quando os cotilédones são removidos no final do desenvolvimento das plântulas dessa espécie, o crescimento e a floração das plantas não são influenciados, sugerindo que os indivíduos já apresentavam capacidade fotossintética para suprir a perda dos cotilédones (Kennedy et al. 2004).

No ambiente natural, as plântulas podem perder seus tecidos de reserva devido à herbivoria dos cotilédones ou à predação das sementes antes de germinarem (Zhang et al. 1997). A predação de sementes desponta como um dos principais fatores responsáveis por efeitos negativos na reprodução das plantas. Ela é considerada um fator chave na mortalidade das sementes, podendo limitar a oferta ou até mesmo impedir a germinação, tendo, portanto, consequências drásticas na trajetória das sementes, na diversidade e na distribuição das plantas em um ecossistema (Pereira 2012). Uma extensa gama de insetos está associada à predação de sementes, tanto no período de pré quanto na pós-dispersão (Zhang et al. 1997). Destacam-se algumas ordens como, por exemplo, Lepidoptera e Hymenoptera, mas os Coleoptera são os que mais possuem representantes que predam sementes de espécies nativas (Zhang et al. 1997, Johnson e Romero 2004).

De acordo com o levantamento realizado por Meiado et al. (2012), os estudos sobre a predação de sementes na Caatinga são raros. Assim, estudos que analisem as espécies afetadas pela predação e os efeitos dessa interação negativa nas sementes são de extrema importância para a conservação das plantas desse ecossistema, principalmente para as espécies ameaçadas de extinção, pois os danos causados por esses animais podem elevar a taxa de mortalidade e reduzir o sucesso reprodutivo das espécies vegetais (Meiado et al. 2012).

Handroanthus spongiosus (Rizzini) S. Grose (Bignoniaceae) é uma espécie arbórea e endêmica da Caatinga, com potencial medicinal, sendo utilizada na arborização urbana, como planta forrageira para bovinos, caprinos e ovinos, além de madeireira (Siqueira Filho et al. 2009). Atualmente, essa espécie encontra-se classificada na categoria de ameaça "em perigo de extinção" (EN), segundo a lista oficial de espécies da flora ameaçadas de extinção (Brasil 2008). Pouco se sabe sobre os fatores que afetam seu sucesso reprodutivo e, em coletas recentes de frutos dessa espécie, foi observada a presença de sementes predadas nos lotes armazenados. Assim, o presente estudo teve o objetivo de avaliar o efeito da predação de sementes de H. spongiosus por microlepidópteros em seu comportamento germinativo e no seu desenvolvimento inicial, bem como analisar se essa interação pode prejudicar o sucesso reprodutivo da espécie.

\section{Material e Métodos}

\section{Local de coleta dos frutos}

Para a análise do efeito da predação de sementes por microlepidópteros na germinação de sementes e no desenvolvimento inicial de plântulas de H. spongiosus, os frutos foram coletados em 10 árvores da espécie estudada no Sítio Morrinho, município de Casa Nova, região Norte do Estado da Bahia (09¹6’20,55’W; 41¹5’03,02”S), no mês de outubro de 2011. A região é caracterizada pelo clima Semiárido (BShW), com precipitação média atual de 409 mm e solos do tipo Neossolo Quartzarênico Órtico (Brasil 2006), sendo considerada uma área prioritária para a conservação da Caatinga, classificada como "Insuficientemente Conhecida” (Brasil 2007).

\section{Germinação das sementes predadas}


Após a coleta, os frutos foram levados para o Laboratório de Sementes (LAS) do Centro de Referência para Recuperação de Áreas Degradadas da Caatinga (CRAD), da Universidade Federal do Vale do São Francisco (UNIVASF), onde as sementes foram beneficiadas e separadas em duas categorias: íntegras e predadas. Para a separação destas categorias, as sementes foram visualizadas em estereomicroscópio óptico, onde se buscou sinais que indicassem a predação das sementes como, por exemplo, a perda de parte de estruturas seminais (i.e., tegumento e tecidos de reserva) e a presença de ovos ou larvas de insetos nas sementes. Sementes sem estes sinais de predação foram consideradas íntegras (Meiado et al. 2013).

Para avaliar o efeito da predação pelos microlepidópteros na germinação de sementes da espécie estudada foram separadas 100 sementes predadas e 100 sementes íntegras, que foram colocadas para germinar em placas de Petri forradas com dupla camada de papel filtro umedecido com água destilada, sendo mantidas em câmara de germinação a $25^{\circ} \mathrm{C}$, sob luz branca e fotoperíodo de 12 horas (Ferreira et al. 2017). A germinação foi avaliada diariamente por um período de 30 dias e o critério para se considerar semente germinada foi a protrusão radicular de tamanho $\geq 2 \mathrm{~mm}$.

\section{Desenvolvimento inicial das plântulas}

Após a análise da germinação, as sementes recém germinadas foram transferidas para recipientes plásticos contendo $500 \mathrm{~g}$ de substrato (areia e húmus na proporção de 1:1), os quais foram mantidos em casa de vegetação por um período de 90 dias, como suprimento hídrico diário por aspersão. Para avaliar o efeito da predação de sementes pelos microlepidópteros no desenvolvimento inicial de H. spongiosus foram cultivadas 120 plântulas, sendo 60 plântulas originadas a partir de sementes íntegras e 60 plântulas originadas a partir de sementes predadas.

\section{Parâmetros mensurados e análises estatísticas}

Ao final das análises foram calculados a germinabilidade (\%), o tempo médio de germinação $\left[\mathrm{t}=\sum n_{i}\right.$ $t_{i} / \sum n_{i}$, onde $t_{i}$ é o período desde o início do experimento até a enésimas observação (dias) e $n_{i}$ é o número de sementes germinadas no tempo i], o índice de velocidade de germinação, adaptado de Maguire (1962) [IVG= $\left(G_{1} / N_{1}\right)+\left(G_{2} / N_{2}\right)+\ldots+\left(G_{n} / N_{n}\right)$, onde $G_{1}, G_{2}$ e $G_{n}$ correspondem ao número de sementes germinadas na primeira, segunda e última contagem, respectivamente, e $\mathrm{N}_{1}, \mathrm{~N}_{2}$ e $\mathrm{N}_{\mathrm{n}}$ representam o número de dias decorridos até a primeira, segunda e última contagem, respectivamente $]$ e o índice de sincronização $\left[\mathrm{E}=-\sum f_{i} \log 2 f_{i}\right.$, onde $f_{i}$ é a frequência relativa da germinação (i.e., a proporção de sementes germinadas em um intervalo)] de acordo com Ranal e Santana (2006).

Para a análise dos parâmetros de desenvolvimento inicial das plântulas foram mensurados o comprimento $(\mathrm{cm})$ e a biomassa seca $(\mathrm{g})$ da parte aérea e subterrânea, o número de folhas $(\mathrm{N})$ e a biomassa seca $(\mathrm{g})$ das folhas de 20 plântulas de cada tratamento, em intervalos de 30 dias entre as três análises, totalizando 90 dias de desenvolvimento inicial. O comprimento da parte aérea e subterrânea foi determinado com o auxílio de um paquímetro digital e a biomassa seca da parte aérea e subterrânea das plântulas, bem como das folhas, foi determinada com o auxílio de uma balança de precisão analítica, após estas estruturas terem permanecido em estufa de secagem a $70^{\circ} \mathrm{C}$, por um período de 72 horas.

Todos os parâmetros de germinação e de desenvolvimento inicial foram comparados pelo teste t de Student. 
A normalidade dos dados e a homogeneidade das variâncias foram verificadas através dos testes Levene e Shapiro Wilk, respectivamente (Zar 1999). Todas as análises estatísticas foram realizadas no programa BioEstat 5.0, com índice de significância igual a 0,05 (Ayres et al. 2007).

\section{Resultados e Discussão}

As sementes de $H$. spongiosus iniciaram a germinação no primeiro dia de análise e apresentaram um padrão germinativo similar entre os tratamentos avaliados (Figura 1). Entretanto, foi observada uma redução significativa na porcentagem final de germinação da espécie estudada. Sementes predadas pelos microlepidópteros apresentaram uma redução de cerca de 50\% na germinabilidade quando comparada com a germinação das sementes íntegras (Tabela 1).

Figura 1 - Frequência diária (\%) de germinação de sementes de Handroanthus spongiosus (Rizzini) S.Grose (Bignoniaceae) predadas e não predadas por microlepidóptera no período de pré-dispersão.

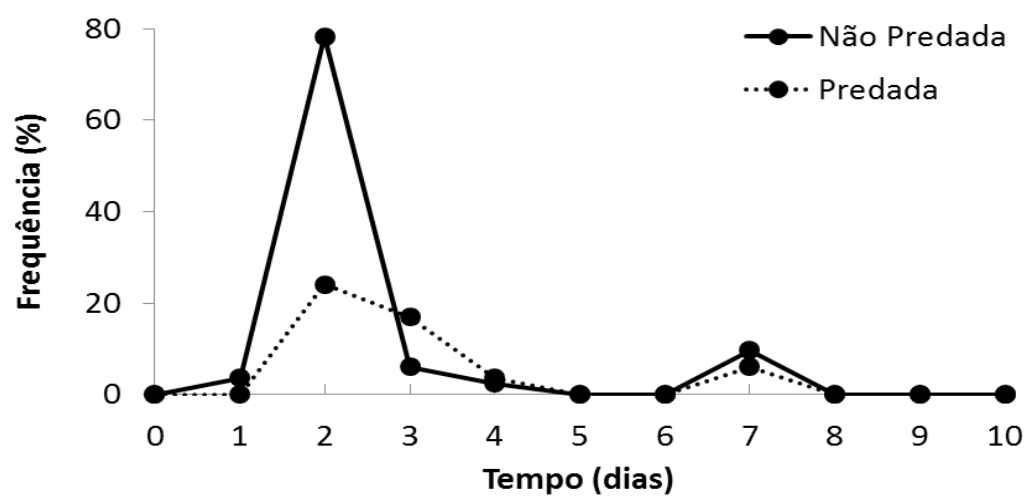

Embora tenha sido observada uma redução na germinabilidade das sementes de H. spongiosus, os demais parâmetros de germinação foram similares entre os tratamentos avaliados (Tabela 1), indicando que a predação das sementes pelos microlepidópteros não alterou o comportamento germinativo das sementes da espécie estudada. A única exceção foi o índice de velocidade de germinação que foi significativamente maior nas sementes íntegras, quando estas foram comparadas com as sementes predadas (Tabela 1).

Tabela 1 - Germinabilidade (G - \%), tempo médio de germinação (TMG - dias), índice de velocidade de germinação (IVG) e índice de sincronização (IS) da germinação de sementes íntegras e predadas de Handroanthus spongiosus (Rizzini) S. Grose (Bignoniaceae). Dados expressos em média \pm desvio padrão. Resultados significativos do teste t de Student em negrito.

\begin{tabular}{lcccc}
\hline Tratamentos & G (\%) & TMG (dias) & IVG & IS \\
\hline Sementes íntegras & $83,0 \pm 7,6$ & $2,53 \pm 0,61$ & $9,70 \pm 1,33$ & $0,90 \pm 0,43$ \\
Sementes predadas & $42,0 \pm 8,3$ & $3,05 \pm 0,61$ & $4,03 \pm 0,78$ & $1,42 \pm 0,33$ \\
\hline T & 6,9702 & $-1,2251$ & 7,3328 & $-1,8827$ \\
Gl & 6 & 6 & 6 & 6 \\
P & $\mathbf{0 , 0 0 0 4}$ & 0,2664 & $\mathbf{0 , 0 0 0 3}$ & 0,1067 \\
\hline
\end{tabular}

Os resultados encontrados no presente estudo indicaram que a predação das sementes de H. spongiosus por microlepidópteros afeta negativamente tanto a germinação das sementes quanto o desenvolvimento inicial das 
plântulas da espécie estudada. Resultados similares foram observados em outras espécies nativas da Caatinga como, por exemplo, em Enterolobium contortisiliquum (Vell.) Morong (Fabaceae) (Meiado et al. 2013). De acordo com os autores, o tamanho das sementes e do inseto predador pode ter relação direta na perda da capacidade germinativa das sementes. Insetos grandes que predam sementes pequenas causam maior mortalidade nas sementes predadas (Meiado et al. 2013). Entretanto, os microlepidópteros observados no presente estudo, embora sejam considerados insetos pequenos, causam uma significativa redução na germinabilidade e alteração no comportamento germinativo da espécie estudada, sugerindo que outros fatores, como o local da predação e a estrutura da semente consumida pelo inseto durante a predação, pode causar a morte das sementes. Finalmente, considerando a existência de outros fatores que impedem a germinação, como agentes patogênicos e condições desfavoráveis do ambiente (Pinto 2007), os resultados do presente estudo tornam-se extremamente expressivos, pois indicam a influência drástica da predação no potencial reprodutivo da espécie estudada.

Por outro lado, embora as sementes tenham conseguido germinar mesmo estando predadas, as plântulas originadas a partir dessas sementes tiveram seu desenvolvimento inicial comprometido. Esse comprometimento pode ser observado na Figura 2, onde fica evidente que a predação de sementes afetou todos os parâmetros morfométricos avaliados nas plântulas da espécie estudada. Na primeira análise de desenvolvimento inicial $\left(30^{\circ}\right.$ dia), não foi observada diferença significativa entre o comprimento da parte aérea das plântulas originadas a partir de sementes íntegras e predadas $(t=-1,0792 ; \mathrm{gl}=39 ; \mathrm{p}=0,2872$; Figura 2). Porém, na análise do mesmo parâmetro no $60^{\circ}$ e $90^{\circ}$ dia, já foi possível observar uma redução significativa de 21,4 e $16,7 \%$, respectivamente $\left(60^{\circ}\right.$ dia: $\mathrm{t}=3,8631 ; \mathrm{gl}=38 ; \mathrm{p}=0,0004$ e $90^{\circ}$ dia: $\mathrm{t}=2,4185 ; \mathrm{gl}=38 ; \mathrm{p}=0,0204 ;$ Figura 2). Por sua vez, $\mathrm{o}$ comprimento da parte subterrânea das plântulas originadas a partir de sementes predadas foi significativamente menor em todas as três análises realizadas durante o desenvolvimento inicial $\left(30^{\circ}, 60^{\circ}\right.$ e $90^{\circ}$ dia $)$, sendo observada uma redução de cerca de $30 \%$ no comprimento da parte subterrânea das plântulas originadas a partir de sementes predadas em cada uma das análises realizadas $\left(30^{\circ}\right.$ dia: $\mathrm{t}=6,7381 ; \mathrm{gl}=38 ; \mathrm{p}<0,0001 ; 60^{\circ}$ dia: $\mathrm{t}=$ 2,5656; $\mathrm{gl}=38 ; \mathrm{p}=0,0143$ e $90^{\circ}$ dia: $\mathrm{t}=3,3190 ; \mathrm{gl}=38 ; \mathrm{p}=0,0020 ;$ Figura 2).

Figura 2 - Comprimento (cm) e biomassa seca (g) da parte aérea (P.A) e subterrânea (P.S) de plântulas de Handroanthus spongiosus (Rizzini) S. Grose (Bignoniaceae) formadas a partir de sementes íntegras e predadas por microlepidóptera no período de pré-dispersão, após 30, 60 e 90 dias de desenvolvimento inicial.

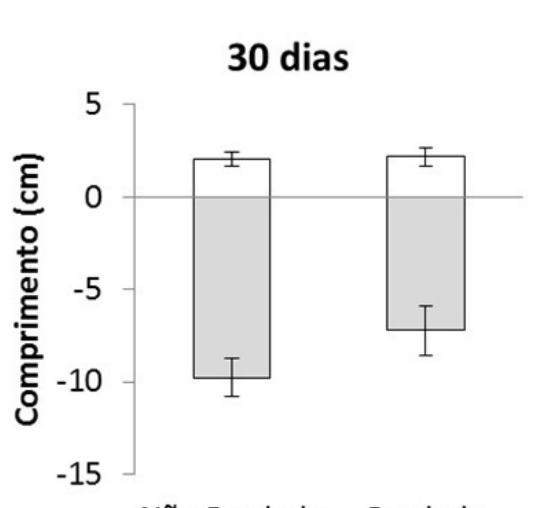

Não Predada Predada

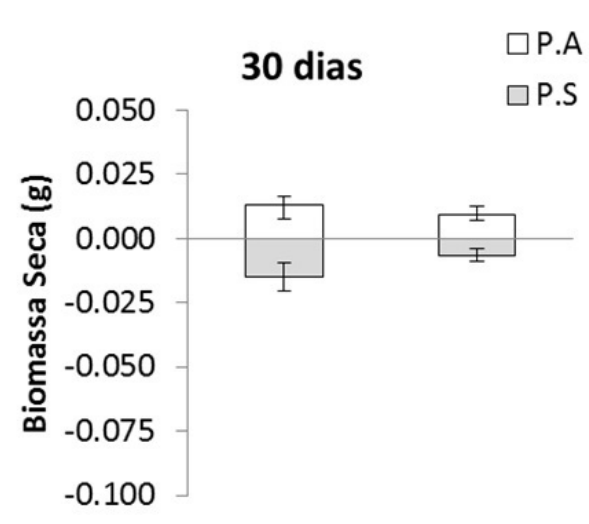

Não Predada Predada 
60 dias

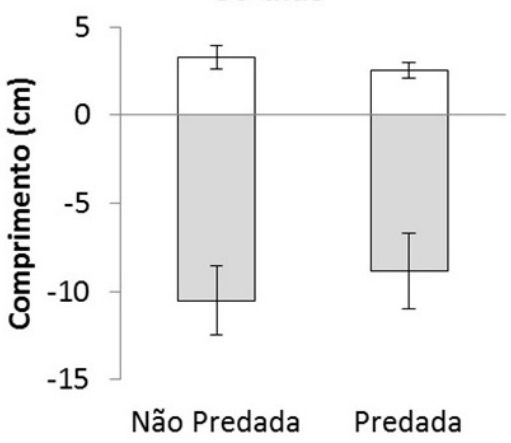

90 dias

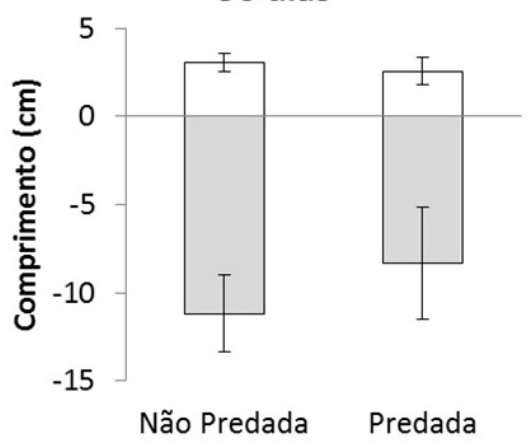

60 dias

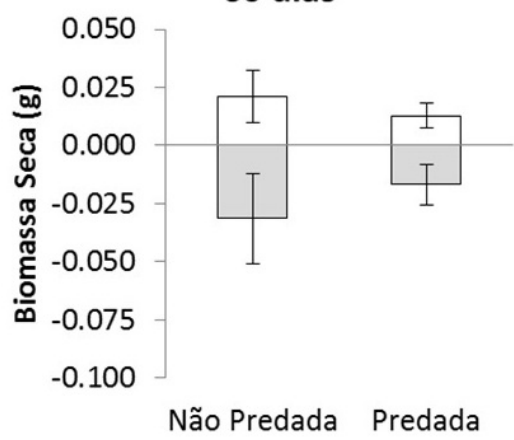

90 dias

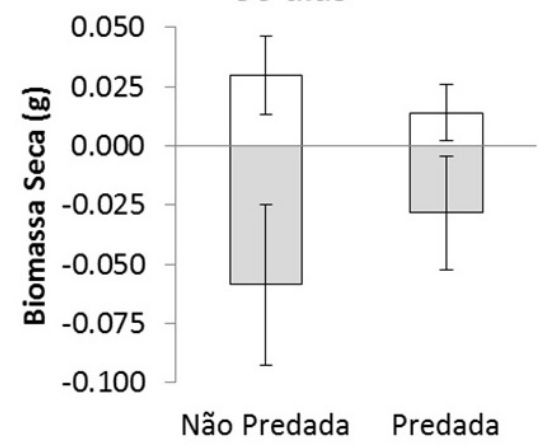

Em relação à biomassa seca das plântulas de $H$. spongiosus, a maior diferença foi observada no $90^{\circ}$ dia de avaliação do desenvolvimento inicial (Figura 2). A biomassa seca da parte aérea das plântulas originadas a partir de sementes íntegras nesse período de avaliação foi 53,4\% maior que a biomassa seca das plântulas originadas a partir de sementes predadas $(t=3,6017 ; \mathrm{gl}=38 ; \mathrm{p}=0,0009$; Figura 2), enquanto que, na parte subterrânea, as plântulas originadas a partir de sementes íntegras apresentaram uma biomassa seca 52,1\% maior que as plântulas originadas a partir de sementes predadas $(t=3,1434 ; \mathrm{gl}=38 ; \mathrm{p}=0,0032$; Figura 2$)$.

O número de folhas foi similar entre as plântulas originadas a partir de sementes íntegras e predadas no $30^{\circ}$ dia de avaliação do desenvolvimento inicial (Tabela 2). Porém, no $60^{\circ}$ e $90^{\circ}$ dia de avaliação, o número de folhas das plântulas originadas a partir de sementes íntegras foi significativamente maior (Tabela 2). Já a biomassa seca das folhas das plântulas originadas a partir de sementes predadas foi significativamente menor nas três avaliações do desenvolvimento inicial, sendo observada uma redução de cerca de 50\% na biomassa seca dessas plantas quando comparadas com as plântulas originadas a partir de sementes íntegras, em cada período de avaliação (Tabela 2).

Tabela 2 - Número de folhas (N) e biomassa seca de folhas (g) de plântulas originadas a partir de sementes íntegras e predadas de Handroanthus spongiosus (Rizzini) S. Grose (Bignoniaceae). Dados expressos em média \pm desvio padrão. Resultados significativos do teste t de Student em negrito.

\begin{tabular}{lcccccc}
\hline & \multicolumn{3}{c}{ Número de folhas (N) } & \multicolumn{3}{c}{ Biomassa seca de folhas (g) } \\
\cline { 2 - 7 } & $\mathbf{3 0}$ & $\mathbf{6 0}$ & $\mathbf{9 0}$ & $\mathbf{3 0}$ & $\mathbf{6 0}$ & $\mathbf{9 0}$ \\
\hline S e mentes & $4,00 \pm$ & $8,85 \pm$ & $10,5 \pm$ & $0,0148 \pm$ & $0,0557 \pm$ & $0,0710 \pm$ \\
íntegras & 1,12 & 1,81 & 1,9 & 0,0049 & 0,0215 & 0,0308 \\
Sementes & $3,7 \pm$ & $6,6 \pm$ & $8,1 \pm$ & $0,0076 \pm$ & $0,0293 \pm$ & $0,0335 \pm$ \\
predadas & 0,7 & 1,85 & 2,65 & 0,0030 & 0,0184 & 0,0237 \\
\hline$T$ & 1,0000 & 3,8866 & 3,2853 & 4,0238 & 4,1416 & 4,1768 \\
Gl & 38 & 38 & 38 & 38 & 38 & 38 \\
$\mathrm{P}$ & 0,3236 & $\mathbf{0 , 0 0 0 4}$ & $\mathbf{0 , 0 0 2 2}$ & $\mathbf{0 , 0 0 0 3}$ & $<\mathbf{0 , 0 0 0 1}$ & $\mathbf{0 , 0 0 0 2}$ \\
\hline
\end{tabular}


Como mencionado anteriormente, foi possível observar diferenças significativas tanto no comprimento quanto na biomassa das plântulas provenientes de sementes predadas e não predadas, sendo que essa diferença também foi observada ao longo dos períodos de avaliação. Esse efeito pode estar associado à remoção de cotilédones durante a predação das sementes. O estudo feito por Boaro et al. (1998) mostrou que os cotilédones têm como finalidade transferir substâncias de reserva à plântula, de modo que gradativamente murcham e caem sendo esses removidos ou predados podem comprometer o desenvolvimento das plântulas, como visto nos resultados do presente estudo.

\section{Conclusão}

Os resultados encontrados neste estudo mostraram que a predação de sementes de $H$. spongiosus por microlepidópteros representam mais uma ameaça ao estabelecimento de novas populações da espécie estudada, uma vez que o sucesso germinativo já é reduzido em cerca de $50 \%$ e as sementes que germinam tem o seu desenvolvimento inicial comprometido. A importância deste estudo também se dar porque H. spongiosus está na lista de espécies ameaçadas de extinção e seu sucesso reprodutivo já está comprometido pela destruição do seu habitat natural e outros fatores como herbivoria por caprinos.

\section{REFERÊNCIAS}

Ayres M, Ayres Júnior M, Ayres DL e Santos AA. 2007. BioEstat - Aplicações estatísticas nas áreas das ciências bio-médicas. Belém: Instituto Mamirauá.

Baskin CC e Baskin JM. 2014. Seeds: Ecology, Biogeography, and Evolution of Dormancy and Germination. San Diego: CA - USA: Academic/Elsevier.

Boaro CSF, Moraes JAPV, Rodrigues JD, Ono EO, Pedra JF e Curi PR. 1998. Magnésio, cálcio e potássio em sementes e cotilédones de feijoeiros e sua transferência para plantas jovens. Pesquisa Agropecuária Brasileira, 33(3): 263-268.

Brasil - Ministério do Planejamento, Orçamento e Gestão, Instituto Brasileiro de Geografia e Estatística. 2006. Sistema Brasileiro de Classificação de Solos. Rio de Janeiro: Instituto Brasileiro de Geografia e Estatística.

Brasil - Ministério do Meio Ambiente. 2007. Áreas Prioritárias para Conservação da Biodiversidade Bioma Caatinga. Brasília: Ministério do Meio Ambiente.

Brasil. Ministério do Meio Ambiente - MMA. 2008. Instrução Normativa nº 6, 23 de setembro de 2008. Brasília: Ministério do Meio Ambiente.

Johnson CD e Romero J. 2004. A Review of Evolution of Oviposition Guilds in the Bruchidae (Coleoptera). Revista Brasileira de Entomologia, 48(3): 401-408.

Kennedy PG, Hausmann NJ, Wenk EH e Dawson TE. 2004. The Importance of Seed Reserves for Seedling Performance: An Integrated Approach Using Morphological, Physiological, and Stable Isotope Techniques. 
Oecologia, 141(4): 547-554.

Maguire JD. 1962. Speed of Germination-aid in Selection and Evaluation for Seedling Emergence and Vigor. Crop Science, 2(1): 176-177.

Meiado MV, Silva FFS, Barbosa DCA e Siqueira Filho JA. 2012. Diásporos da Caatinga: Uma revisão. In: Siqueira Filho JA (Org.). Flora das Caatingas do Rio São Francisco - História Natural e Conservação. Rio do Janeiro: Andrea Jakobsson Estúdio, p.306-365.

Meiado MV, Simabukuro EA e Iannuzzi L. 2013. Entomofauna Associated to Fruits and Seeds of Two Species of Enterolobium Mart. (Leguminosae): Harm or Benefit? Revista Brasileira de Entomologia, 57(1): 100-104.

Melo FPL, Aguiar Neto AV, Simabukuro E e Tabarelli M. 2004. Recrutamento e estabelecimento de Plântulas. In: Ferreira AG e Borgheti F (Org.). Germinação: do básico ao aplicado. Porto Alegre: Artmed, p.237-250.

Pereira CM. 2012. Predação de sementes em Erythrina falcata Benth. Fabaceae - Faboideae: Biologia dos insetos predadores e estratégias de compensação da planta. Dissertação de Mestrado. Guarapuava: Universidade Estadual de Ponta Grossa.

Pinto AA. 2007. Avaliação de danos causados por insetos em sementes de andiroba [(Carapa guianensis Aubl.) e andirobinha (C. procera DC.) (Meliaceae)] na Reserva Florestal Adolpho Ducke em Manaus, AM, Brasil. Dissertação de Mestrado. Manaus: Instituto Nacional de Pesquisas da Amazônia.

Ranal MA e Santana DG. 2006. How and Why to Measure the Germination Process? Revista Brasileira de Botânica, 29(1): 1-11.

Siqueira Filho JA, Santos APB, Nascimento MFS e Espírito Santo FS. 2009. Guia de Campo de Árvores da Caatinga. Petrolina: Gráfica Franciscana, 46p.

Taiz L e Zeiger E. 2006. Fisiologia vegetal. Porto Alegre: Artmed, 618p.

Zar JH. 1999. Biostatistical Analysis. New Jersey: Prentice-Hall Inc., 663p.

Zhang J, Drummond FA, Liebman N, Hatke A. 1997. Insect Predation of Seeds and Plant Population Dynamics. Maine: Maine Agricultural and Forest Experimentation. 